\title{
Evaluation of phytochemical composition and antioxidative, hypoglycaemic and hypolipidaemic properties of methanolic extract of Hemidesmus indicus roots in streptozotocin-induced diabetic mice
}

\author{
Ankita Joshi, Harsha Lad, Harsha Sharma and Deepak Bhatnagar ${ }^{*}$
}

\begin{abstract}
Background: Hemidesmus indicus is an important medicinal plant and extensively used in Ayurvedic and Unani system of medicine. The aim of the study was to evaluate the antioxidant, hypoglycaemic and hypolipidemic potential of methanolic extract of roots of Hemidesmus indicus (HIE) in streptozotocin (STZ) induced diabetic mice.

Methods: HIE was analyzed by LC-MS to determine its phytochemical composition. The in-vitro antioxidant activity of HIE was analyzed through inhibition of free radical scavenging activity (FRSA), total antioxidant power (TAP) and reducing power. Diabetes in mice was induced by a single dose of STZ followed by HIE treatment. The antioxidative, hypoglycaemic and hypolipidemic activity were studied ex-vivo in tissues of diabetic mice.

Results: Phytochemical composition of hemidesmus indicus roots (HIE) revealed the presence of phenols, flavanoids, terpenoids and about 40 different phytoconstituents by LC-MS analysis. Inhibition of lipid peroxidation (LPO) and modulation in superoxide dismutase (SOD), catalase (CAT), glutathione-S- transferase (GST) activity and glutathione (GSH) content showed potent antioxidant activity of HIE in STZ induced diabetic mice, which was also substantiated by in-vitro antioxidant assays. The decrease in fasting blood glucose and serum lipid profile was also observed in mice administered HIE.
\end{abstract}

Conclusion: It is proposed that HIE modulates the oxidant/antioxidant in favor of reducing oxidative stress, hypoglycemia and improved the lipid profile in treated groups.

Keywords: Streptozotocin, Hypoglycaemic, Hypolipidaemic, Lipid peroxidation, Antioxidants, Hemidesmus indicus

\section{Background}

Diabetes mellitus is a complex chronic metabolic disorder characterized by alterations in carbohydrate, protein and fat metabolism. The metabolic changes are caused by the insufficiency of secretion or action of endogenous insulin [1]. Oxidative stress is suggested to be one of the mechanism underlying diabetes and diabetic complications. It results from an oxidant/antioxidant imbalance in favour of oxidants leading to damage of various intracellular components such as proteins, lipids and nucleic acid as

\footnotetext{
* Correspondence: bhatnagarbio@gmail.com

School of Biochemistry, Devi Ahilya University, Khandwa Road, Indore, MP 452017, India
}

well as extracellular matrix components such as proteoglycans and collagens. Free radicals are formed by glucose oxidation, non enzymatic glycation of proteins, oxidative degradation of glycated proteins and increased lipid oxidation (LPO), which may promote oxidative stress and lead to the development of insulin resistance [2]. The harmful effects of oxidative stress are counteracted by the cellular defense mechanism, which consists of enzymes, nonenzymatic and metabolic antioxidants. To treat diabetes various oral antihyperglycaemic agents have been developed over the past years, which include sulphonylureas, biguanides, $\alpha$-glucosidase inhibitors and thiazolidinediones [3]. Hypoglycaemia, lactic acidosis and gastrointestinal 
intolerance are some of the adverse effect of these drugs. These side-effects of synthetic drugs along with drugresistance have led to the resurgence of phytomedicine and search for novel type of antioxidant and antidiabetic from medicinal plants.

Hemidesmus indicus belongs to the family Periplocaceae and is distributed throughout India. Roots and stems of $H$. indicus act as laxative, diaphoretic, diuretic and are useful in treatment of syphilis, cough, asthma and leucoderma. $H$. indicus roots (Fig. 1) contains steroids, terpenoids, flavonoids, saponins, phenolic compounds, tannins and lignins, inulins, cardiac glycosides, proteins and carbohydrates [4]. Pregnenolone glycosides such as hemidesmosides A-C and 2-hydroxy-4-methoxybenzoic acid, 2-hydroxy-4- methoxybenzaldehyde, and 3-hydroxy-4methoxybenzaldehyde were reported in $H$. indicus roots $[5,6]$. These phytoconstituents are accountable for its different biological actions. The phenolic and flavanoid content found in aqueous extract of $H$. indicus corresponds to its reported antioxidant activity [7, 8] The present study was undertaken to investigate the effects of methanolic extract of $H$. indicus roots on lipid peroxidation, antioxidant enzyme activity, lipid profile and fasting blood glucose of STZ induced diabetic mice.

\section{Methods}

\section{Chemicals and reagents}

Streptozotocin, 2,2-diphenyl-1-p-picryl- hydrazyl (DPPH), ursolic acid and quercitrin hydrate were procured from Sigma Chemical Co. St. Louis, Missouri, USA. HPLC grade acetonitrile were purchased from Merck Chemicals, Mumbai, India. Pyrogallol, ethylenediamine tetra acetic acid (EDTA) and other chemicals and solvents of AR grade were purchased from Hi Media Co. Mumbai, India.

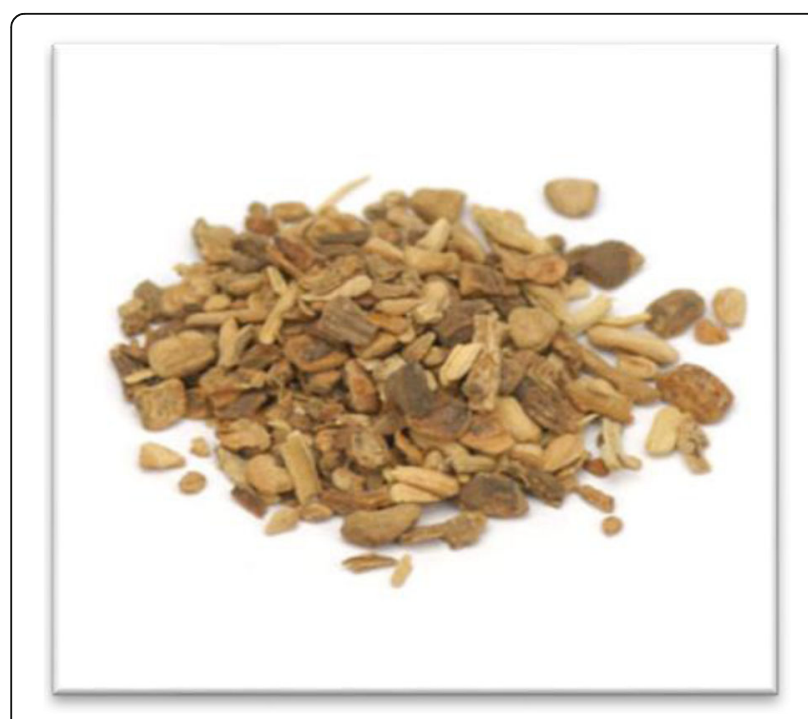

Fig. 1 Roots of Hemidesmus indicus
Plant material and preparation of the extract

$H$. indicus roots were procured from the local market. The plant roots were authenticated by Prof. A.B. Seerwani, Department of Botany, Holkar Science College, Indore. The dried powder of roots of $H$. indicus (HIE) (50 g) were extracted in methanol $(300 \mathrm{ml})$ by the Soxhlet apparatus at $40{ }^{\circ} \mathrm{C}$ for $8 \mathrm{~h}$. The extract was concentrated by evaporation at $35^{\circ} \mathrm{C}$ in water bath. The yield of dried extract was $13.48 \%(w / w)$. The reconstitution of HIE was done in methanol to prepare stock solution of $100 \mathrm{mg} / \mathrm{ml}$ for photochemical and in vitro analysis and in 1\% DMSO for in vivo dosage preparation. These extracts were stored at $4{ }^{\circ} \mathrm{C}$ for analysis.

\section{Animals}

Healthy colony bred mice of Swiss albino strain of both sex weighing $20 \pm 5 \mathrm{~g}$ were kept in polypropylene cages at an ambient temperature. Animals had free access to feed (M.P. Livestock and Poultry Development Corporation, Indore) and water. The experiments were performed according to the guidelines of the Institutional Animal Ethics Committee (IAEC) (CPCSEA/2015/01 dt. 4/7/ 2015). The standard necropsies procedures were carried out at the termination of study to collect the required tissues and blood sample for various analyses from mice of both sexes, as the study does not involve any gender specific parameters.

\section{Total phenol content}

Total phenol content of HIE was determined using the Folin-Ciocalteu method by Singleton and Rossi [9]. Propyl gallate solution $(1 \mathrm{mg} / \mathrm{ml}, 0-30 \mu \mathrm{g})$ was used as standard.

\section{Total flavonoid content}

Total flavonoids were estimated according to the aluminum chloride method of Zhang et al., (2011) [10]. Quercitrin hydrate $(1 \mathrm{mg} / \mathrm{ml}$ in ethanol, $0-250 \mu \mathrm{g})$ was used as a standard.

\section{Total triterpenoid content}

Total triterpenoid content was estimated by the method of Chang and Lin [11]. Ursolic acid (1 $\mathrm{mg} / \mathrm{ml}$ in methanol, $0-50 \mu \mathrm{g})$ was used as standard.

\section{Liquid chromatography-mass spectroscopy (LC-MS)}

LC-MS analysis of the methanolic extract of Hemidesmus indicus roots was carried out using Agilant (6550 iFunnel Q-TOFs) system consisting of Hip sampler, binary pump, column component, Q-TOF having dual ion source and electrospray ion generation (ESI) with Agilent Jet Stream (AJS). Chromatographic separations were performed using $5 \mu \mathrm{l}$ of methanolic sample injected with needle wash onto an Agilent 1290 infinity UHPLC system fitted with a Zorbax Eclipse C18 column $(2.1 \times 150 \mathrm{~mm}, 5 \mu)$ and flow 
rate was $200 \mu \mathrm{l} / \mathrm{min}$. The column was held at $95 \%$ Solvent A (water) and 5\% Solvent B (acetonitrile) for $2 \mathrm{~min}$, followed by an $20 \mathrm{~min}$ step gradient from $5 \%$ B to $95 \%$ B, then 5 min with $5 \% \mathrm{~A}, 95 \% \mathrm{~B}$. Then the elution was achieved with a linear gradient from 5\% A to 95\% A for $4 \mathrm{~min}$. The following parameters were used throughout the MS experiment: for electro spray ionization with positive ion polarity, the capillary voltage was set to $3500 \mathrm{~V}$, the capillary temperature to $250{ }^{\circ} \mathrm{C}$, the nebulizer pressure to $35 \mathrm{psi}$ and the drying gas flow rate to $13 \mathrm{~L} / \mathrm{min}$. Data acquisition and mass spectrometric evaluation were carried out using software Agilent Mass Hunter Qualitative analysis B.06.

\section{Free radical scavenging activity using 1, 1, 2,}

\section{2-diphenyl-p-picryl hydrazyl}

The method is based on the reduction of an ethanolic solution of DPPH by hydrogen donating groups of antioxidant substance [12]. The decrease in DPPH absorption at $517 \mathrm{~nm}$ was measured.

\section{Total antioxidant power using ferric reducing antioxidant power}

The total antioxidant capacity (TAC) of HIE was determined using the ferric reducing antioxidant power (FRAP) [13].

\section{Reducing power}

The reducing power of the test samples was determined according to the method of Oyaizu [14]. The reductive ability was measured by the reduction of $\mathrm{FeCl}_{3}$ in presence of plant extracts. Ascorbic acid dissolved in distil water having concentration ranging from 0 to $17.6 \mu \mathrm{g}$ was used as positive control.

\section{Induction of diabetes}

A single dose of freshly prepared STZ (180 mg/kg body wt.) in cold $0.01 \mathrm{M}$ citrate buffer ( $\mathrm{pH} 4.5)$ was administered intraperitonially to overnight fasted mice to induce diabetes [15]. Streptozotocin causes $\beta$-cell toxicity via mechanism involving both free radical mediated damage and alkylation of DNA [16]. Mice were orally administered $10 \%(w / v)$ glucose for $24 \mathrm{~h}$ after STZ injection to overcome hypoglycaemic shock and after $72 \mathrm{~h}$, fasting blood glucose (FBG) was measured. Mice having FBG levels above $250 \mathrm{mg} / \mathrm{dl}$ were considered diabetic and were selected for further experiments. The FBG of the animals were estimated by glucometer (Akkiscan, Nempro Care, India) at every 3rd day, after the induction of diabetes up to the end of treatment (day 12th). The variation in the body weight during the study period was recorded (provided in Additional file 1) and the food and water intake was monitored in the animals.

\section{Experimental design}

The mice were divided into four groups of 6 animals each. The groups of animals were control mice without any treatment (Group 1), STZ induced diabetic mice (Group $2)$, mice treated with glibenclamide (10 $\mathrm{mg} / \mathrm{kg} /$ day, orally) from $1^{\text {st }}$ day of diabetes induction to 12 th day (Group 3) and mice treated with HIE (35 mg/kg/day, orally) from $1 \mathrm{st}$ to 12th day after the induction of diabetes (Group 4). The animals were observed for the development of diabetes up to day 5 of STZ administration. Treatments in group 3 and 4 were administered to diabetic mice for 12 days after development of diabetes.

\section{Collection and processing of biological samples}

The animals were sacrificed under mild ether anesthesia. Liver and kidney homogenate (10\%) was prepared using Potter-Elvehjem Homogenizer (Remi, Mumbai, India) in ice cold phosphate buffer saline (PBS) $(1: 9, v / v)$ followed by centrifugation at $16000 \mathrm{xg}$ for $30 \mathrm{~min}$ at $4{ }^{\circ} \mathrm{C}$. Blood was collected by cardiac puncture in citrated tubes. Erythrocytes lysate was prepared as described earlier [17]. The supernatant obtained after centrifugation of tissue homogenate and erythrocytes lysate were immediately used to determine antioxidant enzymes and protein content.

\section{Measurement of serum biochemical parameters}

Blood was collected from diabetic and treated groups and the serum samples were analyzed using commercially available kits (Beacon Diagnostics, Navsari, India) for cholesterol, HDL, LDL, VLDL triglycerides by ELISA plate reader (LISA Plus, Rapid Diagnostics, China) and spectrophotometer (Shimadzu, UV-1800, Japan). The quantitative estimations were performed according to the manufacturer's protocol.

\section{Determination of malondialdehyde levels}

Malondialdehyde (MDA) content in liver, kidney and erythrocytes was measured by HPLC method [18].

\section{Determination of antioxidant status}

The activity of superoxide dismutase (SOD), catalase (CAT) and glutathione-S-transferase (GST) was measured in tissue homogenates and erythrocytes lysate. The reduced GSH content was measured in tissue homogenates and blood [19-22].

\section{Statistical analysis}

The results obtained were analyzed by the SPSS software package version 20. The mean values obtained for the different groups were compared by one-way ANOVA, followed by post hoc -Tukeys (HSD) test. 
Table 1 Estimation of phytoconstituents and total antioxidant power of HIE

\begin{tabular}{ll}
\hline Constituents & Content \\
\hline Total phenolic $^{\mathrm{a}}$ & $12.95 \pm 0.77$ \\
Total triterpenoid $^{\mathrm{b}}$ & $79.42 \pm 2.35$ \\
Total flavanoid $^{\mathrm{c}}$ & $57.68 \pm 1.65$ \\
Total antioxidant power $^{\mathrm{d}}$ & $77.36 \pm 1.59$ \\
\hline
\end{tabular}

Values are Mean \pm SE of four experiments

${ }^{a} \mathrm{mg} \mathrm{GAE} / \mathrm{g}$ of dry wt.

${ }^{b} \mathrm{mg}$ UAE /g of dry wt.

c mg QHE/g of dry wt.

${ }^{d} \mu \mathrm{M} / \mathrm{g}$ of dry $w \mathrm{t}$.

\section{Results}

\section{Determination of phytoconstituents}

Phytochemical analysis of HIE was evaluated and the results are represented in Table 1.

\section{Qualitative mass spectral analysis}

HIE showed 73 unique mass signals, out of which putative empirical formulas of 62 compounds were obtained and identified by comparison with phytochemical database \{developed by Sophisticated Analytical Instrument
Facility - Indian Institute of Technology, Bombay (SAIFIITB) and Pubchem $\}$ and details of the compounds are provided in Additional file 1. The MS spectrum of some of the compounds is represented in Fig. 2.

\section{Total antioxidant power using ferric reducing antioxidant} power

The results of total antioxidant power (TAP) using FRAP are presented in Table 1.

\section{Free radical scavenging activity}

HIE showed FRSA by donating the hydrogen atom or electron to stable free radical DPPH. A linear relationship was observed in the DPPH radical scavenging activity and HIE concentrations (Fig. 3a). The FRSA of butylated hydroxyl toluene (BHT, $0.18 \mathrm{mg} / \mathrm{ml}$ ) was found to be $55.51 \pm 0.69 \%$. The $\mathrm{IC}_{50}$ value for $\mathrm{BHT}$ and HIE were 0.06 $\pm 0.02 \mathrm{mg} / \mathrm{ml}$ and $0.10 \pm 0.03 \mathrm{mg} / \mathrm{ml}$ respectively.

\section{Reducing power}

The reduction of $\mathrm{FeCl}_{3}$ in the presence of methanolic extract of HIE was monitored at $700 \mathrm{~nm}$ (Fig. $3 \mathrm{~b}$ ). The higher absorbance of the reaction mixture indicated
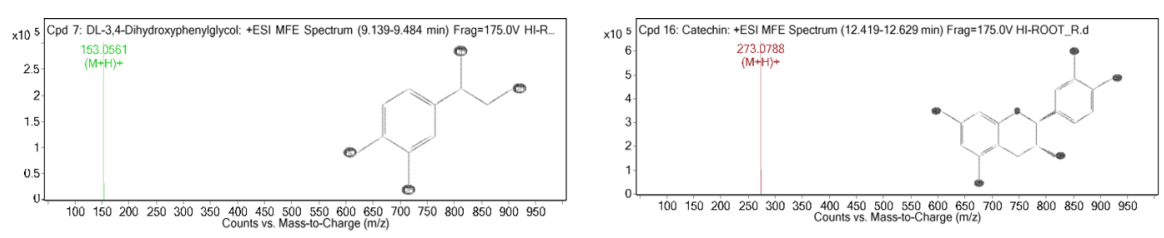

MFE Mszoomed (4-Methyldaphnetin)
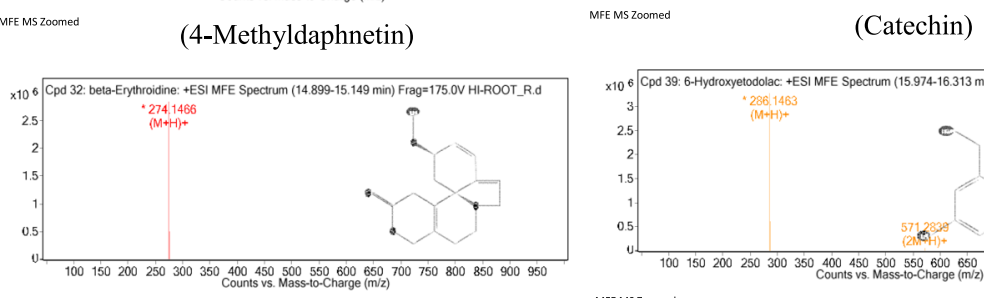

MFE MS zoomed $\quad(\beta$-Erythroidine $)$

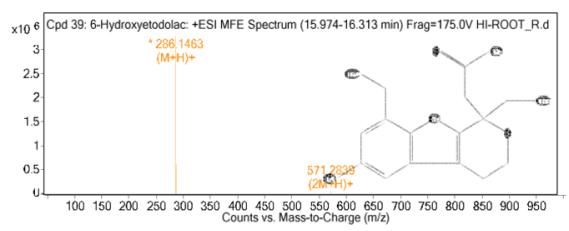

MFE M $2000 \mathrm{med} \quad$ (6-Hydroxyetodolac)

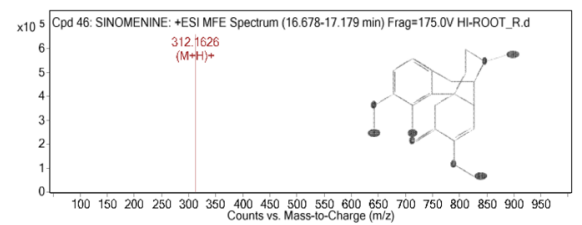

MFE Ms roomed (Sinomenine)

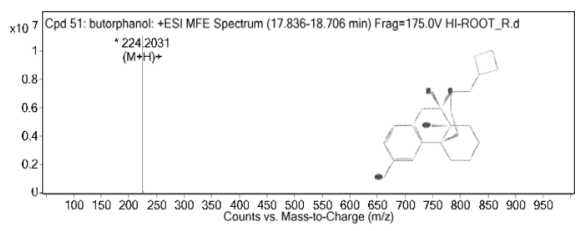

(Butorphanol)

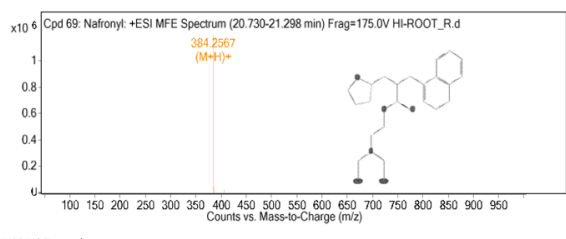

(Nafronyl)

Fig. 2 MFE MS Spectrum of some compounds of HIE detected by LC-MS 


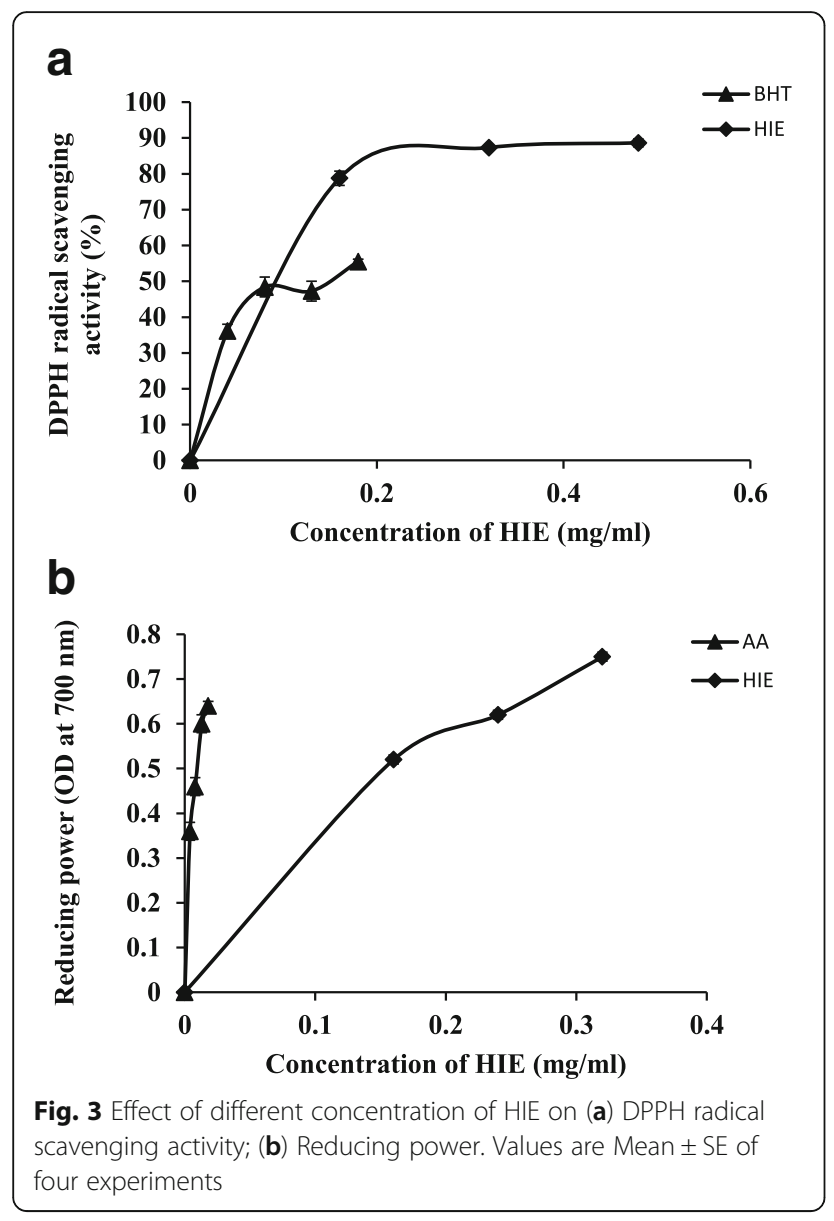

greater reducing power. Ascorbic acid showed the absorbance of $0.64 \pm 0.01$ at the concentration of $176 \mu \mathrm{g} / \mathrm{ml}$.

The total phenolic content of HIE showed a strong and positive correlation with reducing power $(\mathrm{R} 2=0.997, p<$ $0.05)$ and DPPH radical scavenging activity $(\mathrm{R} 2=0.851)$ (Table 2). The total flavanoid content exhibited correlation of $0.997(\mathrm{p}<0.05)$ with reducing power and 0.921 with $\mathrm{DPPH}$ radical scavenging activity. It is suggested that the radical scavenging activity and antioxidant activity of HIE is due to the presence of the phenolic and flavanoid compounds.

Table 2 Correlation coefficient between phytoconstituents and antioxidant properties of HIE

\begin{tabular}{lll}
\hline $\begin{array}{l}\text { Antioxidant Properties } \\
\text { Phyto-Constituents }\end{array}$ & FRSA & RP \\
\hline TPC & & \\
TFC & 0.851 & $0.997^{*}$ \\
TTC & 0.921 & $0.997^{*}$ \\
\hline
\end{tabular}

FRSA Free radical scavenging activity

$R P$ Reducing power

TPC Total phenolic content

TFC Total flavanoid content

TTC Total triterpenoid content

${ }^{*}$ Correlation coefficient is significant at $P<0.05$

\section{Fasting blood glucose and lipid profile}

The effect of HIE on fasting blood glucose is represented in Table 3. Glibenclamide and HIE (Group 3 and 4) produced significant decrease in blood glucose level when compared to the diabetic control (Group 2) after 6 days of treatment. Food intake and body weight showed mild decrease after development of diabetes and non-significant alterations in the body weight was observed in all groups throughout the study period (Additional file 2).

The results showed that there was significant decrease in serum cholesterol, triglycerides, LDL and VLDL in the glibenclamide and HIE treated mice (Table 4; Group 3 and 4) when compared to diabetic control (Group 2).

\section{Determination of MDA levels}

MDA content was found significantly increased in the liver, kidney and erythrocytes of the diabetic group (Table 5; Group 2) as compared to control (Group 1). A significant inhibition in the liver and kidney LPO was observed with glibenclamide (Group 3) and HIE (Group 4) as compared to diabetic control (Group 2). The liver and kidney MDA content of HIE treated group of mice (Group 4) was comparable to that of control group (Group 1). Erythrocytes MDA content remained unaffected in glibenclamide and decreased in HIE treated mice as compare to diabetic control.

\section{Determination of antioxidant status}

The decrease in SOD activity was significant in the liver, whereas it was increased in kidney and erythrocytes in diabetic mice, as compared to control (Table 6; Group 1). Glibenclamide and HIE (Group 3 and 4) significantly elevated the SOD activity in the liver, while in kidney it was comparable to control and in erythrocytes SOD activity was remarkably reduced as compared to diabetic control.

A significant increase in liver, kidney and erythrocyte catalase activity was observed in diabetic animals (Table 6; Group 2) when compared against the control (Group 1). The treatment with glibenclamide (Group 3) significantly decreased the catalase activity in liver, while in erythrocytes and kidney the change was non-significant as compared to diabetic control (Group 2). However, with HIE (Group 4) treatment, liver, kidney and erythrocytes catalase activity is normalized and significantly decreased as compared to diabetic control (Group 2).

GSH content increased in liver and decreased in kidney and erythrocytes of diabetic animal (Group 2) as compared to control (Table 7; Group 1). Glibenclamide treated animal showed low GSH content in liver, while with HIE treatment, the liver GSH content was near to normal. In kidney, both the treatment resulted in recovery of GSH content to normal, whereas for erythrocytes there was no reduction in GSH content in glibenclamide treatment as 
Table 3 Effects of HIE treatment on fasting blood glucose in streptozotocin induced diabetic mice

\begin{tabular}{llllll}
\hline Group & Day 1 & Day 3 & Day 6 & Day 9 & Day 12 \\
\hline 1 & $91.75 \pm 2.78$ & $89.25 \pm 2.72$ & $96.25 \pm 1.49$ & $82.00 \pm 2.27$ & $92.00 \pm 2.55$ \\
2 & $368.25 \pm 12.29^{* *}$ & $294.25 \pm 9.29^{* *}$ & $320.50 \pm 16.06^{* *}$ & $312.25 \pm 17.4^{* *}$ & $321.50 \pm 22.77^{* *}$ \\
3 & $470.00 \pm 22.39^{* * \#}$ & $276.75 \pm 24^{* *}$ & $167.75 \pm 5.71^{* \# \#}$ & $141.50 \pm 6.96^{* \# \#}$ & $112.25 \pm 5.76^{\# \#}$ \\
4 & $541.75 \pm 11.96^{* \# \# \#}$ & $374.57 \pm 23.39^{* *}$ & $243.75 \pm 13.29^{* \# \#}$ & $178.25 \pm 8.12^{* * \# \#}$ & $121.25 \pm 5.22^{\# \#}$ \\
\hline
\end{tabular}

Values are mean \pm SE of 6 animals

${ }^{*} P<0.01,{ }^{* *} P<0.001=$ significant as compared to control (Group 1)

${ }^{\#} P<0.01,{ }^{\# \#} P<0.001=$ significant as compared to diabetic control (Group 2)

Values of FBG are in $\mathrm{mg} \%$

compared to diabetic mice. Increase in GSH content of erythrocytes was observed in HIE as compared to diabetic group (Group 2).

GST activity in tissues and erythrocytes was significantly increased in diabetic animals (Table 7; Group 2) when compared against a control (Group 1), GST activity was not improved by the treatment with glibenclamide (Group 3) as compared to diabetic mice. HIE (Group 4) significantly reduced the liver and erythrocytes GST activity when compared to diabetic control (Group 2) whereas it is restored to normal in kidney.

\section{Discussion}

ROS produced in various tissues leads to tissue injury as well as early events related to the development of diabetes mellitus and its complications [23]. HIE may have beneficial effects on type 1 and 2 diabetes, as the mechanism of development of both the diabetes involve oxidative stress. However, the animal model used represents only type 1 diabetes. Traditional plant remedies have been used in the treatment of diabetes but only a few have been scientifically evaluated [24]. Methanolic extract of $H$. indicus roots contained high quantity of flavanoid and triterpenoid than phenolic content and contributes to the observed antioxidant potential of the extract. The LC-MS analysis coupled with putative identification of compounds indicated the presence of phenolic and flavanoids such as DL-3,4-dihydroxyphenyl glycol, catechin, amiloxate (cinnamic acid derivative); 4-methyldaphnetin (coumarin), terpenoid such as punctaporin B and podocarpatriene derivative. Various alkaloids such as ecgonine, homatropine, $\beta$-erythroidine, butorphanol, securinine along with other phytoconstituents such as phytosterols, lactones, prostaglandins, amino acids, lipids and fatty acids were also identified. Cholesterol lowering triparanol and nafronyl, which enhances cellular oxidative capacity and nudifloramide an end product of NAD degradation shown to potentially inhibit PARP-1 were found in HIE. Natural compounds having anti-inflammatory activity such as safroglycol, etodolac derivative, anisodamine, $\beta$ santonin, nabumetone and securinine were identified by their molecular peak (base peak) [25-28].

The results of free radical scavenging activity showed that HIE reduced DPPH free radical to non-radical DPPH$\mathrm{H}$ by compounds having hydroxyl groups (catechin) or compounds, which oxidise readily (sinomenine). The phenolics, flavanoids, diterpene and sesquiterpene compounds present in HIE can donate hydrogen to terminate the odd electrons of the DPPH radical. The scavenging ability of HIE can be attributed to these bioactive compounds. The higher FRAP value represents high total antioxidant power of HIE. The phenolic compounds reduce $\mathrm{Fe}^{3+}$ to $\mathrm{Fe}^{2}{ }^{+}$and interrupt free radical chain reaction, either by hydrogen atom or electron transfer process and form phenoxyl radical [29]. The reducing power of HIE was positively correlated with the total phenolic, flavanoid and triterpenoid content also evident from mass spectral analysis. $H$. indicus is an edible plant and contains significant amount of total phenolics and reported to have antioxidant activity [30]. An earlier report by Rajan et al., [31] also showed the antioxidant activity of roots of $H$. indicus having

Table 4 Effects of HIE treatment on serum lipid profile in streptozotocin induced diabetic mice

\begin{tabular}{llllll}
\hline Group & Cholesterol $^{a}$ & Triglycerides $^{a}$ & HDL $^{a}$ & LDL $^{a}$ & $V^{2}$ \\
\hline 1 & $125.03 \pm 6.28$ & $35.90 \pm 7.68$ & $101.82 \pm 2.50$ & $83.88 \pm 3.76$ & $7.18 \pm 1.53$ \\
2 & $274.32 \pm 15.82^{* *}$ & $63.90 \pm 2.05^{*}$ & $73.11 \pm 3.17^{*}$ & $160.84 \pm 5.26^{* *}$ & $12.78 \pm 0.41^{*}$ \\
3 & $122.74 \pm 7.09^{\# \#}$ & $32.25 \pm 6.24^{\# \#}$ & $113.31 \pm 5.59^{\# \#}$ & $117.36 \pm 7.59^{* \# \#}$ & $6.45 \pm 1.25^{\# \#}$ \\
4 & $122.77 \pm 9.89^{\# \#}$ & $32.99 \pm 0.18^{\# \#}$ & $122.74 \pm 2.10^{\# \#}$ & $117.84 \pm 5.87^{* \# \#}$ & $6.6 \pm 0.04^{\# \#}$ \\
\hline
\end{tabular}

Values are mean \pm SE of 6 animals

${ }^{*} P<0.01,{ }^{* * *} P<0.001=$ significant as compared to control (Group 1)

${ }^{\#} P<0.01,{ }^{\# \#} P<0.001=$ significant as compared to diabetic control (Group 2)

${ }^{\mathrm{a}} \mathrm{mg} \%$ 
Table 5 Effect of HIE on liver, kidney and erythrocytes LPO in STZ induced diabetic mice

\begin{tabular}{llll}
\hline $\mathrm{LPO}^{\mathrm{a}}$ & & & \\
\hline Group & Liver & Kidney & Erythrocytes \\
\hline 1 & $31.72 \pm 1.43$ & $70.50 \pm 6.16$ & $\mathrm{ND}$ \\
2 & $308.04 \pm 18.10^{*}$ & $340.53 \pm 10.71^{*}$ & $37.08 \pm 2.51^{*}$ \\
3 & $133.75 \pm 8.78^{* \#}$ & $64.52 \pm 6.17^{\#}$ & $40.66 \pm 1.23^{*}$ \\
4 & $33.77 \pm 1.99^{\#}$ & $58.82 \pm 9.17^{\#}$ & $21.89 \pm 0.86^{* \#}$ \\
\hline
\end{tabular}

Values are mean \pm SE of 6 animals

${ }^{*} P<0.001=$ significant as compared to control (Group 1)

${ }^{\#} P<0.001=$ significant as compared to diabetic control (Group 2). $\mathrm{ND}=$ Not Detected

apicomoles of MDA formed/mg protein for liver and kidney and nanomoles of MDA formed/gm $\mathrm{Hb}$ for erythrocytes

quantifiable amounts of phenolic compounds, tannins and flavonoids, as observed in the present study.

Free radicals are formed in diabetes by glucose autoxidation, polyol pathway and non-enzymatic glycation of proteins [32]. Streptozotocin selectively acts on pancreatic $\beta$-cells and cause enhanced ROS in pancreas, liver and other tissues. Increased ROS results in tissue damage and enhanced LPO i.e., oxidation of membrane lipid. Increased MDA in liver, kidney and erythrocytes of diabetic animals than those of control was due to ROS mediated propagation of chain reaction. The increase in MDA content may be due to diminished activity of an antioxidant defense system to sufficiently scavenge free radicals generated in STZ induced diabetes. It has been reported that the increase in MDA associated with diabetes may be reversed by treatment with combined vitamins $C, E$, and $\beta$-carotene [33]. HIE treatment showed a marked inhibition in LPO and thereby reduction in MDA content probably due to inhibition of propagation of LPO. Cellular defense mechanisms, which act against free radicals, include GSH and antioxidant enzymes such as SOD, CAT and GST respectively whose activities contribute to eliminate superoxide, hydrogen peroxide and hydroxyl radicals [34]. The activity of these antioxidant enzymes critically influences the susceptibility of various tissues to oxidative stress and is associated with the development of complications in diabetes. The superoxide radicals are dismutated by SOD to form hydrogen peroxide followed by its decomposition into water and oxygen by catalase. Liver SOD activity was decreased in diabetic animals as compared to control. This may be due to excessive production of superoxide radical that inhibit the activity of SOD, which consequently improved after HIE treatment. The increased activity of kidney and erythrocytes SOD in diabetic mice may be a response to combat minor generation of ROS upon STZ administration, which was normalized in HIE treated diabetic mice. The increased activity of the liver, kidney and erythrocytes catalase was observed in STZ induced diabetes that was significantly restored by HIE. The elevation of CAT activity may be endogenous compensatory mechanism for prolonged over production of free radicals and oxidative stress [35].

Glutathione (GSH) efficient antioxidant present in almost all living cells and is considered as one of the biomarker of redox imbalance at cellular level. The present study showed decreased kidney and erythrocytes GSH content in diabetic control, which may be considered to be an indicator of increased free radical scavenger in the repair of radical caused biological damage. HIE treatment restores the GSH content, whereas glibenclamide treatment does not affect GSH content of STZ induced diabetic mice. Both liver GSH content and GST activity were increased in diabetic control suggesting that cellular antioxidant defense mechanism was triggered by STZ induced generation of ROS. There was a significant decrease in both liver GSH content and GST activity upon HIE treatment probably due to the up regulation of GSH redox system in liver to counteract oxidative stress, as GSH also act as cofactor for GST in this system.

The reduction in FBG upon HIE treatment in STZ induced diabetic mice, indicates that HIE has high antidiabetic potential probably due to the insulin secretagogue and antioxidative action of the $H$ indicus root extract. Hyperglycaemia stimulates ROS formation and resulting oxidative stress triggers hyperglycaemia induced diabetic complications [36]. The hypoglycaemic and antioxidative effect of HIE may prevent development and progression of diabetic complications.

Table 6 Effect of HIE on SOD and CAT in STZ induced diabetic mice

\begin{tabular}{|c|c|c|c|c|c|c|}
\hline \multicolumn{4}{|l|}{$\mathrm{SOD}^{a}$} & \multicolumn{3}{|l|}{$C A T^{b}$} \\
\hline Group & Liver & Kidney & Erythrocytes & Liver & Kidney & Erythrocytes \\
\hline 1 & $19.19 \pm 0.50$ & $6.34 \pm 0.10$ & $120.83 \pm 4.64$ & $199.96 \pm 7.94$ & $187.28 \pm 5.13$ & $693.76 \pm 89.77$ \\
\hline 2 & $2.97 \pm 0.05^{* * *}$ & $13.92 \pm 0.21^{* * *}$ & $263.95 \pm 9.96^{* * * \#}$ & $312.66 \pm 1.44^{* * *}$ & $243.86 \pm 10.68^{*}$ & $1652.21 \pm 85.34^{* * *}$ \\
\hline 3 & $8.25 \pm 0.37^{* * * \#}$ & $5.32 \pm 0.12^{* * \#}$ & $128.97 \pm 5.98^{\#}$ & $219.78 \pm 6.54^{\#}$ & $204.07 \pm 11.69^{\mathrm{NS}}$ & $1444.72 \pm 27.18^{* * *}$ \\
\hline 4 & $7.95 \pm 0.69^{* * * \#}$ & $6.96 \pm 0.17^{\#}$ & $27.34 \pm 2.28^{* * * \#}$ & $209.79 \pm 5.44^{\#}$ & $168.99 \pm 5.63^{\#}$ & $523.57 \pm 76.07^{\#}$ \\
\hline
\end{tabular}

Values are mean \pm SE of 6 animals

${ }^{*} P<0.05,{ }^{* *} P<0.01,{ }^{* * * *} P<0.001=$ significant as compared to control (Group 1)

${ }^{\#} P<0.001$ = significant as compared to diabetic control (Group 2). ${ }^{\text {NS }}$ Not significant

anits/mg protein

${ }^{\mathrm{b}} \mu$ moles $\mathrm{H}_{2} \mathrm{O}_{2}$ decomposed/min/mg protein 
Table 7 Effect of HIE on GSH and GST and in STZ induced diabetic mice

\begin{tabular}{|c|c|c|c|c|c|c|}
\hline \multicolumn{4}{|l|}{$\overline{\mathrm{GSH}^{\mathrm{a}}}$} & \multicolumn{3}{|l|}{$G_{S T} T^{b}$} \\
\hline Group & Liver & Kidney & Erythrocytes & Liver & Kidney & Erythrocytes \\
\hline 1 & $19.27 \pm 0.62$ & $25.33 \pm 0.45$ & $25.05 \pm 0.91$ & $0.33 \pm 0.06$ & $0.36 \pm 0.07$ & $10.22 \pm 0.40$ \\
\hline 2 & $31.60 \pm 1.98^{*}$ & $15.78 \pm 0.39^{*}$ & $7.31 \pm 1.11^{*}$ & $4.24 \pm 0.42^{*}$ & $1.37 \pm 0.13^{*}$ & $18.10 \pm 1.45^{*}$ \\
\hline 3 & $13.93 \pm 1.78^{\# \#}$ & $25.66 \pm 1.61^{\# \#}$ & $7.94 \pm 0.21^{*}$ & $1.76 \pm 0.23^{* \# \#}$ & $1.11 \pm 0.08^{*}$ & $19.94 \pm 1.61^{*}$ \\
\hline 4 & $22.04 \pm 0.67^{\#}$ & $38.26 \pm 0.61^{* \# \#}$ & $13.82 \pm 0.56^{* \# \#}$ & $0.16 \pm 0.02^{\# \#}$ & $0.30 \pm 0.05^{\# \#}$ & $6.97 \pm 0.30^{\# \#}$ \\
\hline
\end{tabular}

Values are mean \pm SE of 6 animals

${ }^{*} P<0.001=$ significant as compared to control (Group 1)

${ }^{\#} P<0.01,{ }^{\# \#} P<0.001=$ significant as compared to diabetic control (Group 2)

${ }^{a}$ nanomoles of DTNB conjugated/mg protein for liver and kidney and $\mu$ moles of DTNB conjugated/gm Hb for erythrocytes

${ }^{\mathrm{b}} \mu \mathrm{moles}$ of GSH conjugated $/ \mathrm{min} / \mathrm{mg}$ protein

Certain oxidative stress related defects in oxidative phosphorylation machinery and mitochondrial $\beta$-oxidation lead to excess accumulation of intracellular triglyceride in muscle and liver and subsequent insulin resistance [37]. As compared to diabetic control, glibenclamide and HIE treated mice, the total cholesterol, triglyceride, LDL and VLDL were significantly lowered with increased HDL indicating recovery of normal lipid metabolism in STZ induced diabetes. The results showed that HIE was found to be effective against diabetic dyslipidaemia.

\section{Conclusion}

The methanolic extract of $H$. indicus roots contains various phytoconstituents having potent antioxidant, hypoglycaemic and hypolipidaemic activity. Oral administration of HIE, lowers the FBG of STZ induced diabetic mice as well as it modulates the intracellular antioxidant defense to overcome the oxidative damage and improves the serum lipid profile. It is suggested that the roots of $H$. indicus may serve as an important hypoglycaemic and hypolipidaemic agent to protect the cells by mitigating oxidative stress induced toxicity in STZ induced diabetes.

\section{Additional files}

Additional file 1: Putative identification of compounds in HIE. (DOCX $17 \mathrm{~kb}$ )

Additional file 2: Effects of HIE treatment on body weight of streptozotocin induced diabetic mice. (DOCX 14 kb)

\section{Abbreviations}

AJS: Agilent Jet Stream; CAT: Catalase; DPPH: 2,2-diphenyl-1-p-picrylhydrazyl; ESI: Electrospray ion generation; FBG: Fasting Blood Glucose; FRAP: Ferric Reducing Antioxidant Power; FRSA: Free Radical Scavenging Activity; GSH: Glutathione; GST: Glutathione-S- Transferase; HDL: High Density Lipoprotein; HIE: Methanolic extract of Hemidesmus indicus roots; LC-MS: Liquid Chromatography-Mass Spectroscopy; LDL: Low Density Lipoprotein; LPO: Lipid Peroxidation; MDA: Malondialdehyde; NAD: Nicotinamide-adenine dinucleotide; PARP-1: Poly ADP ribose polymerase-1; PBS: Phosphate Buffer Saline; ROS: Reactive Oxygen Species; SOD: Superoxide Dismutase; STZ: Streptozotocin; TAP: Total Antioxidant Power; VLDL: Very Low Density Lipoprotein

\section{Acknowledgements}

We acknowledge SAIF- IIT Bombay, India for providing LC-MS facility for analysis of samples. AJ is thankful to University Grant Commission, New Delhi for providing Golden Jubilee Fellowship under UGC XIIth Plan grant.

\section{Funding}

The funding from Golden Jubilee Fellowship under University Grant Commission, New Delhi (UGC XII ${ }^{\text {th }}$ Plan) was provided to Ankita Joshi for this research work.

\section{Availability of data and materials}

Not applicable

\section{Authors' contributions}

AJ: designed and performed the experiments, participated in data analysis and manuscript preparation. HL, HS and DB: participated in design of experiments and helped in manuscript preparation. All authors read and approved the final manuscript.

\section{Ethics approval}

The experimental mice were treated following the ethical guidelines of Institutional Animal Ethics Committee (IAEC) constituted under supervision of CPCSEA (Committee for the Purpose of Control and Supervision of Experiments on Animals). The experimental procedures were approved by the IAEC (CPCSEA/2015/01 dt. 4/7/2015) of Devi Ahilya University, India.

\section{Consent for publication}

Not applicable

\section{Competing interests}

The authors declare that they have no competing interests.

\section{Publisher's Note}

Springer Nature remains neutral with regard to jurisdictional claims in published maps and institutional affiliations.

Received: 10 July 2017 Accepted: 24 January 2018

Published online: 26 February 2018

\section{References}

1. Alberti KG, Zimmet PZ. New diagnostic criteria and classification of diabetes-again. Diabet Med. 1998;15:535-6.

2. Wolff SP, Jiang ZY, Hunt JV. Protein glycation and oxidative stress in diabetes mellitus and ageing. Free Radic Biol Med. 1991;10:339-52.

3. Scheen AJ, Lefèbvre PJ. Oral antidiabetic agents a guide to selection. Drugs. 1998;55:225-36

4. Lakshmi T, Rajendran R. Hemidesmus indicus commonly known as Indian sarasaparilla- an update. Int J Pharm Bio Sci. 2013;4:397-404.

5. Zhao Z, Matsunami K, Otsuka H, Negi N, Kumar A, Negi DS. A condensed phenylpropanoid glucoside and pregnane saponins from the roots of Hemidesmus indicus. J Nat Med. 2013;67:137-42.

6. Fiori J, Leoni A, Fimognari C, Turrini E, Hrelia P, Mandrone M, lannello C, Antognoni F, Poli F, Gotti R. Determination of phytomarkers in 
pharmaceutical preparations of Hemidesmus indicus roots by micellar electrokinetic chromatography and high-performance liquid chromatography-mass spectrometry. Anal Lett. 2014;47:2629-42.

7. Ravikiran T, Shilpa S, Praveen Kumar N, Sowbhagya R, Anand S, Anupama SK, Bhagyalakshmi D. Antioxidant activity of Hemidesmus indicus (L.) r.Br. Encapsulated poly (lactide-co-glycolide) (PLGA) nanoparticles. J Pharm Biol Sci. 2016;11:9-17.

8. Kumar S, Pooja M, Harika K, Haswitha E, Nagabhushanamma G, Vidyavathi N. In-vitro antioxidant activities, total phenolics and flavonoid contents of whole plant of Hemidesmus indicus (Linn.). Asian J Pharm Clin Res. 2013;6:249-51.

9. Singleton VL, Rossi JA. Colorimetry of total phenolics with phosphomolybdicphosphotungstic acid reagents. Am J Enol Vitic. 1965;16:144-58.

10. Zhang L, Ravipati AS, Koyyalamudi SR, Jeong SC, Reddy N, Smith PT, Münch G, Wu MJ, Satyanarayanan M, Vysetti B. Antioxidant and anti-inflammatory activities of selected medicinal plants containing phenolic and flavonoid compounds. J Agr Food Chem. 2011:59:12361-7.

11. Chang CL, Lin CS. Phytochemical composition, antioxidant activity, and neuroprotective effect of Terminalia chebula Retzius extracts. Evid Based Compliment Alternat Med. 2012; https://doi.org/10.1155/2012/125247.

12. Mellors A, Tappel AL. The inhibition of mitochondrial peroxidation by ubiquinone and ubiquinol. J Biol Chem. 1966:241:4353-6.

13. Benzie IF, Strain JJ. The ferric reducing ability of plasma as a measure of antioxidant power: the FRAP assay. Anal Biochem. 1996;239:70-6.

14. Oyaizu M. Studies on product of browning reaction prepared from glucosamine. Jpn J Nutr. 1986;44:307-15.

15. Arora S, Ojha SK, Vohora D. Characterisation of streptozotocin induced diabetes mellitus in swiss albino mice. Glob J Pharmacol. 2009;3:81-4.

16. Lenzen S. The mechanisms of alloxan- and streptozotocin-induced diabetes. Diabetologia. 2008;51:216-26.

17. Kale M, Rathore N, John S, Bhatnagar D. Lipid peroxidative damage on pyrethroid exposure and alteration in antioxidant status in rat erythrocytes: a possible involvement of reactive oxygen species. Toxicol Lett. 1999;105: 197-205.

18. Tukozkan N, Erdamar H, Seven I. Measurement of total malondialdehyde in plasma and tissue by high performance liquid chromatography and thiobarbituric acid assay. Firat Tip Dergisi. 2006;11:88-92.

19. Marklund S, Marklund G. Involvement of the superoxide anion radical in autoxidation of pyrogallol and convenient assay for superoxide dismutase. Eur J Biochem. 1974;47:469-74.

20. Aebi H. Catalase. In: Bergmeyer HU, editor. Methods in enzymatic assay. 3rd ed. New York: Academic press; 1983. p. 276-86.

21. Habig WH, Pabst MJ, Jakoby WB. Glutathione-S-transferase, the first enzymatic step in mercapturic acid formation. J Biol Chem. 1974;249:7130-9.

22. Beutler E, Duran O, Kelly BM. Improved method for determination of blood glutathione. J Lab Clin Med. 1963;61:882-8.

23. Maritim AC, Sanders RA, Watkins JB 3rd. Diabetes, oxidative stress, and antioxidants: a review. J Biochem Mol Toxicol. 2003;17:24-38.

24. Gupta RK, Kesari AN, Diwakarc S, Tyagia A, Tandona V, Chandra R, Watal G. In vivo evaluation of anti-oxidant and anti-lipidimic potential of Annona squamosa aqueous extract in type 2 diabetic models. J Ethnopharmacol. 2008;118:21-5.

25. Steinberg D, Avigan J, Feigelson EB. Effects of triparanol (mer-29) on cholesterol biosynthesis and on blood sterol levels in man. J Clin Invest. 1961;40:884-93.

26. Martindale - the Extra Pharmacopoeia' (30th ed), edited by J. E. F. Reynolds. Pp 1310. London: The Pharmaceutical Press. 1993. ISBN 0853693005.

27. Shibata K, Mushiage M, Kondo T, Hayakawa $T$, Tsuge $H$. Effects of vitamin $B_{6}$ deficiency on the conversion ratio of tryptophan to niacin. Biosci Biotechnol Biochem. 1995;59:2060-3.

28. Galvez-Llompart M, Zanni R, Domenech RG. Modeling natural antiinflammatory compounds by molecular topology. Int J Mol Sci. 2011;12: 9481-503.

29. Steenken S, Neta P. One-electron redox potentials of phenols. Compounds of biological interest. J Phys Chem. 1982;86:3661-7.

30. Jayawardena N, Watawana MI, Waisundara WY. Evaluation of the total antioxidant capacity, polyphenol contents and starch hydrolase inhibitory activity of ten edible plants in an in vitro model of digestion. Plant Foods Hum Nutr. 2015;70:71-6.

31. Rajan S, Shalini R, Bharathi C, Aruna V, Thirunalasundari T, Brindha P. In vitro antioxidant screening of Hemidesmus indicus root from South India. Asian J Pharm Biol Res. 2011;1:222-31.
32. Obrosova IG, Fathallah L, Greene DA. Early changes in lipid peroxidation and antioxidative defense in diabetic rat retina: effect of DL-a-lipoic acid. Eur J Pharmacol. 2000;398:139-46.

33. Mekinova D, Chorvathova V, Volkovova K, Staruchova M, Grancicova E, Klvanova J, Ondreic R. Effect of intake of exogenous vitamins C, E and $\beta$-carotene on the antioxidative status in kidneys of rats with streptozotocin-induced diabetes. Nahrung. 1995;39:257-61.

34. Soto C, Recoba R, Barron C, Alverez C, Favari L. Silymarin increases antioxidant enzymes in alloxan-induced diabetes in rat pancreas. Comp Biochem Physiol. 2003;136:205-12.

35. Aksoy N, Vural H, Sabuncu T, Aksoy S. Effect of melatonin on oxidativeantioxidative status of tissues in streptozotocin induced diabetic rats. Cell Biochem Funct. 2003;21:121-5.

36. Valko M, Leibfritz D, Moncola J, Cronin MT, Mazura M, Telser J. Free radicals and antioxidants in normal physiological functions and human disease. Int J Biochem Cell Biol. 2007;39:44-84.

37. Rosca MG, Mustata TG, Kinter MT, Ozdemir AM, Kern TS, Szweda LI, Brownlee M, Monnier VM, Weiss MF. Glycation of mitochondrial proteins from diabetic rat kidney is associated with excess superoxide formation. Am J Physiol-Renal Physiol. 2005;289:F420-30.

\section{Submit your manuscript to a SpringerOpen ${ }^{\circ}$ journal and benefit from:}

- Convenient online submission

- Rigorous peer review

- Open access: articles freely available online

- High visibility within the field

- Retaining the copyright to your article

Submit your next manuscript at $>$ springeropen.com 